\title{
Hyaluronic acid-functionalized single-walled carbon nanotubes as tumor-targeting MRI contrast agent
}

This article was published in the following Dove Press journal:

International Journal of Nanomedicine

16 July 2015

Number of times this article has been viewed

\author{
Lin Hou* \\ Huijuan Zhang* \\ Yating Wang \\ Lili Wang \\ Xiaomin Yang \\ Zhenzhong Zhang \\ School of Pharmaceutical Sciences, \\ Zhengzhou University, Zhengzhou, \\ People's Republic of China \\ *These authors contributed equally \\ to this work
}

Correspondence: Zhenzhong Zhang

School of Pharmaceutical Sciences,

Zhengzhou University, No 100,

Kexue Road, Zhengzhou 45000I,

People's Republic of China

Tel $+8637 \mid 67781910$

Fax +86 37| 6778 I908

Email zhangzz08@I26.com
Abstract: A tumor-targeting carrier, hyaluronic acid (HA)-functionalized single-walled carbon nanotubes (SWCNTs), was explored to deliver magnetic resonance imaging (MRI) contrast agents (CAs) targeting to the tumor cells specifically. In this system, HA surface modification for SWCNTs was simply accomplished by amidation process and could make this nanomaterial highly hydrophilic. Cellular uptake was performed to evaluate the intracellular transport capabilities of HA-SWCNTs for tumor cells and the uptake rank was HA-SWCNTs $>$ SWCNTs owing to the presence of HA, which was also evidenced by flow cytometry. The safety evaluation of this MRI CAs was investigated in vitro and in vivo. It revealed that HA-SWCNTs could stand as a biocompatible nanocarrier and gadolinium (Gd)/HA-SWCNTs demonstrated almost no toxicity compared with free $\mathrm{GdCl}_{3}$. Moreover, $\mathrm{GdCl}_{3}$ bearing HA-SWCNTs could significantly increase the circulation time for MRI. Finally, to investigate the MRI contrast enhancing capabilities of Gd/HA-SWCNTs, $\mathrm{T}_{1}$-weighted MR images of tumor-bearing mice were acquired. The results suggested Gd/HA-SWCNTs had the highest tumor-targeting efficiency and $\mathrm{T}_{1}$-relaxivity enhancement, indicating HA-SWCNTs could be developed as a tumor-targeting carrier to deliver the $\mathrm{CAs}, \mathrm{GdCl}_{3}$, for the identifiable diagnosis of tumor.

Keywords: gadolinium, magnetic resonance, SWCNTs, hyaluronic acid, contrast agent

\section{Introduction}

Magnetic resonance imaging (MRI) is one of the most powerful and noninvasive modalities in diagnostic clinical medicine and biomedical research. ${ }^{1}$ Compared to other imaging modalities, MRI has its own unique advantages. First, it has the ability to penetrate into tissue deeply to provide excellent soft tissue contrast with up to sub-millimeter resolution. Second, it can provide high-quality anatomical imaging without employing ionizing radiation. Finally, it can also give information about the physicochemical state of the tissue, flow diffusion, and motion. ${ }^{2,3}$ So in the last decade, MRI has undergone a "quantum leap" for diagnosis of a variety of diseases and conditions.

Although MRI has inherent contrast to distinguish different tissues from one another, administration of an external chemical contrast agent (CA) is a common practice in the clinic to improve disease detection by increasing sensitivity and diagnostic confidence. ${ }^{4}$ Otherwise, MR images would be fairly featureless since the amount of water does not vary significantly in the various tissues in the body. So far, various paramagnetic compounds have been evaluated as MRI CAs, and they are classified into two types: 1) spin-lattice relaxation agents $\left(\mathrm{T}_{1}\right.$-shortening agents like paramagnetic $\mathrm{Gd}^{3+}, \mathrm{Mn}^{2+}$, etc) or 2) spin-spin relaxation agents $\left(\mathrm{T}_{2}\right.$-shortening agents like superparamagnetic 
iron oxide nanoparticles). The most widely used in cancer imaging are chelated gadolinium (Gd) compounds, ${ }^{5}$ such as Gd(III)-diethylenetriaminepentaacetic acid ([Gd-DTPA $]^{-2}$ ) (Magnevist, Bayer Healthcare, Leverkusen, Germany) ${ }^{6}$ and $\mathrm{Gd}(\mathrm{III})-\mathrm{N}, \mathrm{N}^{\prime}, \mathrm{N}^{\prime \prime}, \mathrm{N}^{\prime \prime \prime}$-tetracarboxymethyl-1,4,7,10tetraazacyclod-odecane $\left([\mathrm{Gd}(\mathrm{DOTA})]^{-1}\right)$ (Dotarem, Bloomington, IN). ${ }^{7,8}$ However, these agents suffer from poor sensitivity and rapid renal clearance, which severely limits the time window for MRI. ${ }^{7}$ Furthermore, no targeted CA is available for clinical MR cancer molecular imaging.

Recent progress in Gd3t carbon nanotube complexes has promoted the development of high-relaxivity $\mathrm{T}_{1}$ MRI CAs. ${ }^{9}$ Since their discovery in 1991, carbon nanotubes have been explored so many different possibilities for various technological applications. ${ }^{10,11}$ Single-walled carbon nanotubes (SWCNTs) are the materials studied most commonly due to its most applications in biological and medical fields. They have been developed for a wealth of applications, such as usage as DNA biosensors, protein biosensors, and ion channel blockers. ${ }^{12}$ Moreover, SWCNTs can effectively shuttle various biomolecules, such as drugs, peptide, proteins, DNA, and RNA, into cells by endocytosis. ${ }^{13,14}$ Moreover, SWCNTs are unique imaging probes with great potential in biomedical multimodal imaging. ${ }^{15}$ There were some reports saying that the internal loading of US-tubes with aqueous $\mathrm{GdCl}_{3}$ could greatly improve the effectiveness of its relaxation. ${ }^{16}$ Additionally, the multi-sites of SWCNTs could bind with drugs or molecular targets effectively. ${ }^{17}$ All these results suggested a new way of tumor-targeting CA delivery system for MRI.

Nevertheless, SWCNTs, because of very high long-range van der Waals forces of attraction, have a tendency to aggregate together and are difficult to disperse. In other words, they are insoluble in most organic solvents so that their poor processability is prevented in many applications. ${ }^{18}$ As a result, a major goal in CNTs chemistry is functionalization, which generates chemical moieties on their surfaces, for improvement of solubility and biocompatibility. ${ }^{19-21}$ The functionalized CNTs are believed to be very promising in the field of biological technologies, such as gene expression and drug delivery. ${ }^{22,23}$

Hyaluronic acid (HA) is a naturally occurring linear polysaccharide with negative charge, which exists widely in extracellular matrix and is primarily cleared by the lymphatic system. ${ }^{24} \mathrm{HA}$ has a series of excellent properties, such as biocompatible, biodegradable, and non-immunogenic characteristics. $^{25,26}$ The expression of receptors for HA was reported to have a close relation with the occurrence of tumors. Many tumor cells showed up-regulated expression of receptors for HA, resulting in HA having a high affinity for tumors. ${ }^{27}$ It has been demonstrated that HA nanoparticles showed rapid uptake into tumor cells and can enter tumor cells through receptor-mediated endocytosis, based on the interactions between the HA of nanoparticles and CD44 of tumor cells. ${ }^{28}$

In this study, a tumor-targeting carrier, HA-functionalized SWCNTs was explored to deliver MRI CAs targeting to the tumor cells specifically (Figure 1). In this system, HASWCNTs bearing $\mathrm{GdCl}_{3}$ could significantly reduce the toxicity of $\mathrm{Gd}^{3+}$ and increase the circulation time for MRI.

\section{Materials and methods Materials}

$\mathrm{GdCl}_{3}$ (purity $>99.9$ wt $\%$ ) was purchased from Sinopharm Chemical Reagent Co., Ltd (Shanghai, People's Republic of China). Short SWCNTs (purity $>90.0 \mathrm{wt} \%$, optical density 1-2 nm, length 5-30 $\mu \mathrm{m}$, special surface area $>380 \mathrm{~m}^{2} / \mathrm{g}$ and $\mathrm{EC}>100 \mathrm{~s} / \mathrm{cm}$ ) were purchased from Chengdu Organic Chemicals Co. Ltd, Chinese Academy of Sciences (Chengdu, People's Republic of China). HA (purity $>98 \%$, molecular weight (MW) 12,000 kDa), ethylenediamine, formamide, N-hydroxysuccinimide (NHS), N-(3-dimethylaminopropyl$\mathrm{N}^{\prime}$-ethylcarbodiimide) hydrochloride $(\mathrm{ED} \cdot \mathrm{HCl})$, fluorescein isothiocyanate (FITC), sulforhodamine B (SRB), and dimethyl sulfoxide (DMSO), triethylamine were obtained from Sigma-Aldrich (St Louis, MO, USA). Soybean lecithin (PC) and poloxamer 188 were got from BASF (Ludwigshafen, Germany). Penicillin, streptomycin, and fetal bovine serum were bought from Life Technologies (Carlsbad, CA, USA).

\section{Synthesis and characterization of HA-SWCNTs Oxidation of SWCNTS}

After being purified with $12 \mathrm{M} \mathrm{HNO}_{3}$, SWCNTs (80 mg) were added to $40 \mathrm{~mL}$ of mixture acid $\left(\mathrm{HNO}_{3}: \mathrm{H}_{2} \mathrm{SO}_{4}=1: 3\right)$ and ultrasonicated in a water bath for 4 hours at room temperature. The resulting solid products (SWCNTs-COOH) were then collected on a membrane filter (Millipore, pore size $0.22 \mu \mathrm{m}$, MembraPure $\mathrm{GmbH})$, followed by rinsing thoroughly with Milli-Q water (Volchy Enviroment Company) and dried in vacuum at $60^{\circ} \mathrm{C}$ for 24 hours.

\section{Amine-functionalized $\mathrm{HA}$}

HA (MW $=12,000 \mathrm{kDa}, 100 \mathrm{mg}$ ) were added to $30 \mathrm{~mL}$ of formamide, heating in an oil bath at $50^{\circ} \mathrm{C}$ until dissolved. Then $\mathrm{EDC} \cdot \mathrm{HCl}(250 \mathrm{mg})$ and NHS (150 mg) were added to this solution, followed by activation with stirring for 30 minutes. After that $1.0 \mathrm{~mL}$ of ethylenediamine was added 


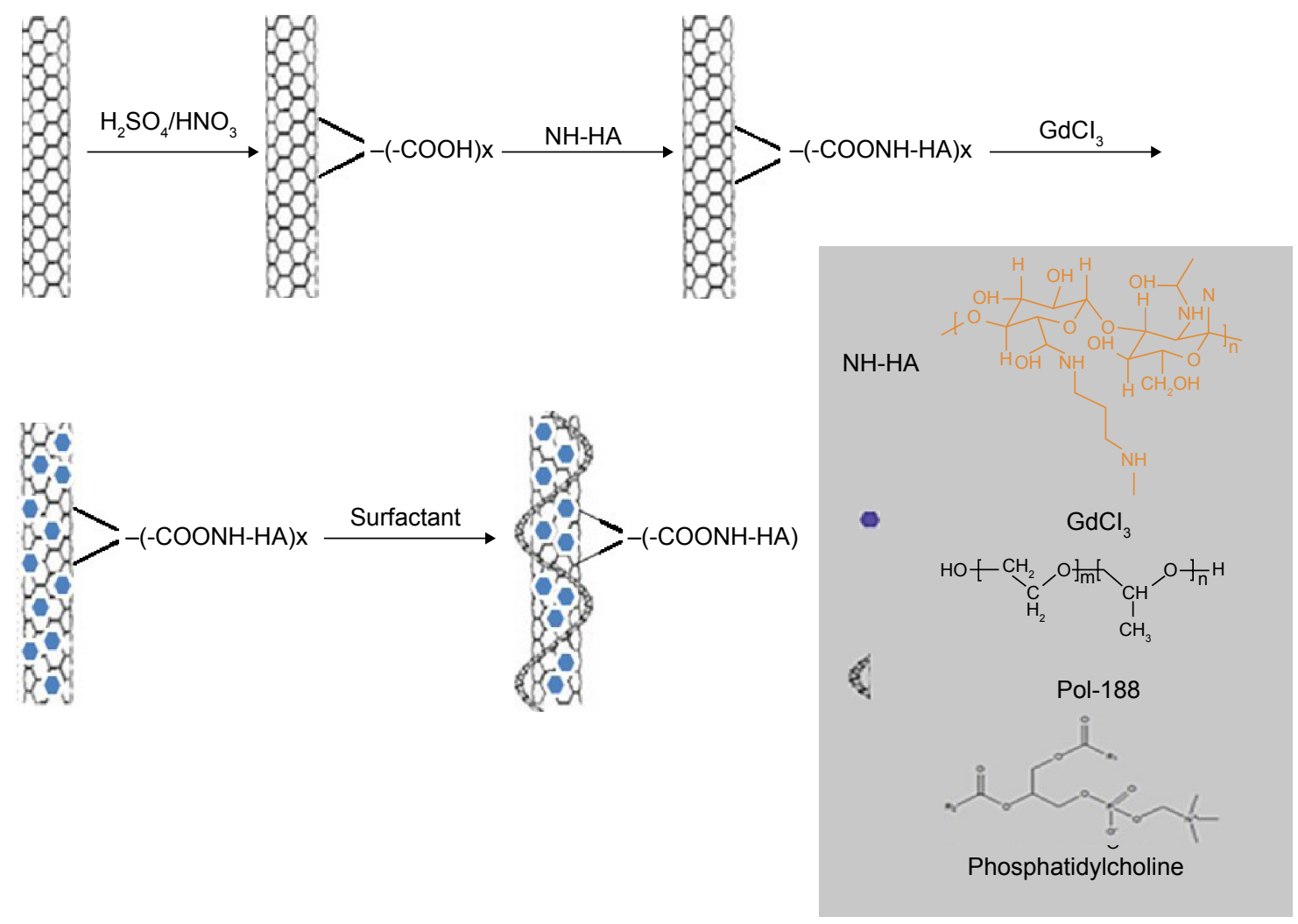

Figure I Schematic illustration of the formation for this MRI contrast agent. Abbreviation: MRI, magnetic resonance imaging.

to the activated HA solution drop by drop in the ice bath and reacted at room temperature for 2 hours. The reaction solution was cooled by excess precooled acetone. The crystallization was then collected on a membrane filter (Millipore, pore size $0.22 \mu \mathrm{m}$ ), followed by rinsing thoroughly with acetone. Finally, the precipitation was redissolved with water and dialyzed by a dialysis bag ( $\mathrm{MW}=3,500 \mathrm{kDa}$ ) for 48 hours to remove acetone, EDC, and NHS. At last, the synthesis products $\left(\mathrm{HA}-\mathrm{NH}_{2}\right)$ were freeze-dried in vacuum for 24 hours.

\section{Synthesis of HA-SWCNTs}

SWCNTs-COOH and HA-NH $\mathrm{NH}_{2}$ were added to formamide, sonicated until dissolved; then $\mathrm{EDC} \cdot \mathrm{HCl}$ and $\mathrm{NHS}$ were added to this solution and stirred for 15 minutes at room temperature. After that, $180 \mu \mathrm{L}$ of triethylamine was added to the activated solution drop by drop in the ice bath and reacted at room temperature for 24 hours. The reaction solution was cooled with excess precooled acetone and centrifuged at $10,000 \mathrm{rpm}$ for 15 minutes. Finally, the precipitation was redissolved with water and dialyzed by a dialysis bag (MW $=12,000 \mathrm{kDa}$ ) for 48 hours to remove free HA and then the synthesis products (HA-SWCNTs) were freeze-dried in vacuum for 24 hours.
Dynamic light scattering (Zetasizer Nano ZS-90, Malvern Instruments, Malvern, UK) and transmission electron microscopy (FEI; Tecnai G2 20 S-TWIN, FEI, the Netherlands) were used for characterizing particle size, zeta potential and morphological changes of HA-SWCNTs, respectively. The optical properties of SWCNTs and HA-SWCNTs were characterized using an ultraviolet-visible (UV-Vis) spectrometer (LAMBDA 35, PerkinElmer, Waltham, MA, USA). Fourier transform infrared spectra were recorded on a Nicolet iS10 spectrometer (Thermo Scientific, Waltham, MA, USA). The relative amount of HA grafted to SWCNTs was tested using a Thermogravimetric Analyzer (PerkinElmer) with the experimental conditions of scanning from $30^{\circ} \mathrm{C}$ to $800^{\circ} \mathrm{C}$ under nitrogen at a heating rate of $20^{\circ} \mathrm{C} / \mathrm{min}$.

\section{Construction of Gd/HA-SWCNTs Construction of Gd/HA-SWCNTs}

HA-SWCNTs $(20 \mathrm{mg})$ were added to ultrapure water $(10 \mathrm{~mL})$ and then sonicated using an ultrasonic cell disruption system ( $200 \mathrm{~W}, 30$ times) in ice bath to get an excellent aqueous dispersion. Then $\mathrm{GdCl}_{3}$ aqueous solution was added to the dispersion drop wise and magnetically stirred for 30 minutes. After precipitate was collected by centrifugation at 10,000 rpm, 
the product was redispersed by addition of PC solvent using an ultrasonic cell disruption system (300 W, 20 times). And then the nanosuspension was dialyzed by a dialysis bag ( $\mathrm{MW}=12,000 \mathrm{kDa}$ ) for 24 hours to remove free $\mathrm{GdCl}_{3}$. The resulting products $(\mathrm{Gd} / \mathrm{HA}-\mathrm{SWCNTs})$ were freeze-dried in vacuum for 24 hours, and then stored at $4^{\circ} \mathrm{C}$ until use.

\section{Determination of loading efficiency}

Gd/HA-SWCNTs nanosuspension was diluted with 10 times the amount of ultrapure water, and then dilution was divided into two portions. One dilution was used to determine the absorbance $(A)$ at $808 \mathrm{~nm}$ with a UV spectrophotometer to calculate the carrier content according to the standard curve $\mathrm{C}_{\text {SWCNTs }}=338.80 \times A-0.6127$ (unit: $\mu \mathrm{g} / \mathrm{mL}$ ). The other dilution was used to determine $\mathrm{Gd}^{3+}$ response values $(Y)$ by an inductively coupled plasma-optical emission spectrometry (ICP-OES) instrument to calculate the amount of $\mathrm{GdCl}_{3}$ loading on HA-SWCNTs with the standard curve $Y=13389 \mathrm{C}_{\mathrm{Gd}^{-}}{ }^{-}$ 19540 (unit: $\mu \mathrm{g} / \mathrm{mL}$ ). Then the loading efficiency (LE) could be obtained by following formula:

$\underset{(w t \%)}{\mathrm{LE}}=\frac{\text { Amount of } \mathrm{GdC1} 1^{3}}{\text { Amount of } \mathrm{GdC} 1^{3}+\text { Amount of HA-SWCNTs }} \times 100 \%$

\section{Cellular uptake}

MCF-7 mice melanoma cell line was obtained from Chinese Academy of Sciences Cell Bank. Cells were cultured in normal Dulbecco's Modified Eagle's Medium with 10\% fetal bovine serum and $1 \%$ penicillin/streptomycin in $5 \% \mathrm{CO}_{2}$ and $95 \%$ air at $37^{\circ} \mathrm{C}$ in a humidified incubator.

To evaluate the intracellular uptake capacity of HASWCNTs in MCF-7 cell line, fluorescence microscopy and flow cytometry analysis were used. FITC, a fluorescence probe, was incorporated into SWCNTs as well as HASWCNTs by mixing of these samples with FITC according to the following method: FITC in DMSO $(1 \mathrm{mg} / \mathrm{mL}, 50 \mu \mathrm{L})$ was added to HA-SWCNTs nanosuspension $(4.0 \mathrm{~mL})$ and ultrasonicated with ultrasonic cell disruption system to obtain HA-SWCNTs-FITC. Excess FITC was removed by Sephadex G-25 column (Sigma-Aldrich Co., St Louis, MO, USA). MCF-7 cells ( $3 \times 10^{6}$ cells per well) were seeded on glass cover slips in six-well plates. When cells reached $70 \%$ confluence, they were treated with SWCNTs-FITC and HASWCNTs-FITC (SWCNTs concentration: $10 \mu \mathrm{g} / \mathrm{mL}$ ) for 0.5 hours, 1 hour, 3 hours, and 6 hours, respectively. At the designated time points, cells were washed with phosphate buffered saline followed by fixing for 30 minutes with $70 \%$ ethanol, then cells were observed under a fluorescence microscope (Eclipse 80i, Nikon Corporation, Tokyo, Japan), or trypsinized, collected by centrifugation, and suspended in phosphate buffered saline for flow cytometry analysis.

\section{Safety evaluation of Gd/HA-SWCNTs}

\section{Safety evaluation in vitro}

The cytotoxicity of Gd/HA-SWCNTs to MCF-7 cells was assessed by using standard sulforhodamine B assay. The MCF-7 cells were cultured and seeded at a density of $5 \times 10^{3}$ cells/well into 96-well plates and incubating for 24 hours. The medium was then replaced with fresh medium containing various concentrations of free $\mathrm{GdCl}_{3}, \mathrm{Gd} / \mathrm{SWCNTs}$, Gd/HA-SWCNTs, and Gd-DTPA for 24 hours. At last standard sulforhodamine $\mathrm{B}$ assay was carried out to determine cell viabilities.

\section{Safety evaluation in vivo}

Pathological changes of tissues can be displayed using hematoxylin-eosin (H\&E) technique. Hereby it was taken in this experiment to examine the toxicity of CA in different tissues of mice. The mice were divided into five groups (nine mice per group), minimizing the differences of weights in each group. $0.2 \mathrm{~mL}$ of $\mathrm{GdCl}_{3}, \mathrm{Gd} / \mathrm{SWCNTs}, \mathrm{Gd} / \mathrm{HA}-\mathrm{SWCNTs}$, or Gd-DTPA (Gd dose: $1 \mathrm{mM} / \mathrm{kg}$ ) in saline were intravenous injected into mice via the tail vein. Three mice were killed in every group at the $1 \mathrm{st}, 5$ th, and 10 th day after treatment. Then the tissues of mice were collected and soaked in $10 \%$ formalin solution, embedded with paraffin for H\&E stain. Morphological changes were observed under microscope (Zeiss LSM 510, Carl Zeiss Meditec AG, Jena, Germany).

\section{Targeting efficiency study}

\section{Xenograft tumor mouse model}

All animal experiments were performed under a protocol approved by Henan Laboratory Animal Center. Mice melanoma tumor models were generated by subcutaneous injection of $2 \times 10^{6} \mathrm{~S} 180$ cells in $0.2 \mathrm{~mL}$ saline into the right shoulder of male BALB/c mice (18-22 g, Henan laboratory animal center). The mice were used when the tumor volume reached approximately $100 \mathrm{~mm}^{3}$ ( 4 days after tumor inoculation).

\section{Accumulation of Gd in tumor}

For targeting efficiency studies, the tumor-bearing mice were fasted for 12 hours before treatment, but had access to water ad libitum. The mice were divided into four groups (five mice per group), minimizing the differences of weights in each group. $0.2 \mathrm{~mL}$ of $\mathrm{GdCl}_{3}, \mathrm{Gd} / \mathrm{SWCNTs}$, Gd/HA-SWCNTs, or Gd-DTPA (Gd dose: $1 \mathrm{mM} / \mathrm{kg}$ ) in saline were intravenously 
injected into mice via the tail vein, respectively. After treatment for 0.5 hour, 1 hour, 3 hours, 6 hours, and 24 hours, tumor tissues were collected, weighed, and homogenized in $0.9 \% \mathrm{NaCl}$ saline solution. Gd in tumor tissues was determined by ICP-OES instrument after nitration using nitric acid.

The biodistribution of the CA in organs such as liver, kidney, and spleen was also detected by measuring the quantity of Gd in the internal organs through ICP-OES and observing the localization of Gd through histopathological analyses, respectively. To support the MRI results, the mice were killed and the organs were recovered and digested using acid solution $\left(\mathrm{HClO}_{4}-\mathrm{H}_{2} \mathrm{O}_{2}, 50: 50 \mathrm{v} / \mathrm{v}, 30\right.$ minutes $)$.

\section{In vivo imaging analysis Optical imaging in vivo}

In order to investigate the dynamic behaviors and targeting ability of HA-SWCNTs nanocarriers on tumor-bearing mice, HA-SWCNTs nanoparticles were labeled with the near-infrared fluorescence (NIRF) dye, 1,1'-dioctadecyltetramethyl indotricarbocyanine iodide (DiR), to monitor in vivo biodistribution and tumor accumulation ability according to the method for Gd-loaded HA-SWCNTs. The preparation of nanotubes loaded with DiR was same as that of its Gd-loaded counterparts, except that $20 \mu \mathrm{L}$ DiR ( $5 \mathrm{mg} / \mathrm{mL}$ stock solution in dichloromethane) was added to $1 \mathrm{~mL}$ water contained HA-SWCNTs before primary emulsification. The obtained formulation was dialyzed against water to remove unencapsulated DiR. Noninvasive optical imaging system was utilized. When the tumor volume reached approximately $500-1,000 \mathrm{~mm}^{3}$, mice were injected with free $\operatorname{DiR}(5 \mathrm{mg} / \mathrm{kg}$, diluted in Cremophor EL/ethanol $/ 5 \%$ of glucose, 1:1:9, v/v/v) as the control and DiR-labeled HASWCNTs nanoparticles $(5 \mathrm{mg} / \mathrm{kg})$ via the tail vein. NIRF imaging experiments were performed at 1 hour, 3 hours, 6 hours, 12 hours, and 24 hours post-injection using a Kodak in vivo imaging system FX PRO (Kodak, New Haven, CT, USA) equipped with an excitation bandpass filter at $730 \mathrm{~nm}$ and an emission at $790 \mathrm{~nm}$. Images were analyzed using the Kodak Molecular Imaging Software 5.X (Kodak, USA).

\section{Magnetic resonance imaging}

For in vivo MRI, the tumor-bearing mice were divided into three groups (five mice per group). $0.2 \mathrm{~mL}$ of $\mathrm{Gd} / \mathrm{SWCNTs}$, Gd/HA-SWCNTs, or Gd-DTPA (Gd dose: $1 \mathrm{mM} / \mathrm{kg}$ ) in saline were intravenously injected into mice via the tail vein, respectively. Then the mice were anesthetized with isoflurane in an anesthesia apparatus and MRI was conducted on a 7-T clinical MRI scanner (Bruker BioSpin GmbH, Ettlingen,
Germany) at $37^{\circ} \mathrm{C}$ under the conditions ( $\mathrm{T}_{1}$ weighted image: repetition time/echo time $1,300 \mathrm{~ms} / 7.5 \mathrm{~ms}$, thickness of $1.0 \mathrm{~mm}$, layer spacing of $1.2 \mathrm{~mm}$, field of view of $4.0 \mathrm{~cm}$, flip of $180^{\circ}$, matrix of $256 \times 256$, bandwidth of $83333.3 \mathrm{~Hz}$, echo spacing of $7.5 \mathrm{~ms}$ ).

\section{Results and discussion Synthesis and characterization of HA-SWCNTs}

To improve the solubility and biocompatibility of SWCNTs, HA-derivatization was performed via condensation of carboxyl of SWCNTs-COOH and the $\mathrm{NH}_{2}$ group of $\mathrm{HA}-\mathrm{NH}_{2}$, as depicted in Figure 1. Based on thermal gravimetric analysis, Fourier transform infrared, and UV-Vis absorbance spectra, the successful synthesis of HA-SWCNTs was realized (Figure 2). First, $\mathrm{HA}-\mathrm{NH}_{2}$ was synthesized and confirmed by the strong $\mathrm{C}-\mathrm{N}$ stretching vibration absorption peak $\left(1,111.67 \mathrm{~cm}^{-1}\right)$ and $\mathrm{N}-\mathrm{H}$ bending vibration bands (antisymmetric peak: $1,637.66 \mathrm{~cm}^{-1}$; symmetric peak: $1,617.70 \mathrm{~cm}^{-1}$ ) (Figure 2Ab). Then HA was grafted onto SWCNTs to get HA-SWCNTs (Figure 2Aa), which was confirmed by the typical $\mathrm{C}=\mathrm{O}$ stretching vibration absorption at $1,723.36 \mathrm{~cm}^{-1}$, $\mathrm{C}-\mathrm{N}$ stretching vibration absorption at $1,106.10 \mathrm{~cm}^{-1}$ and $\mathrm{N}-\mathrm{H}$ bending vibration band at $1,654.14 \mathrm{~cm}^{-1}$, suggesting that the amide bond between SWCNTs and HA was synthesized successfully. Moreover, UV-Vis absorbance spectra were also used to verify the product. As shown in Figure 2B, SWCNTs (Figure 2Bb) displayed a characteristic absorption peak at $264 \mathrm{~nm}$ while $\mathrm{HA}-\mathrm{NH}_{2}$ (Figure 2Bc) showed no characteristic peaks but only absorption in the ultraviolet terminal. After HA grafted onto SWCNTs, the water-soluble HA-SWCNTs (Figure 2Ba) carrier not only retained the typical peak of SWCNTs at $264 \mathrm{~nm}$, but also showed the ultraviolet terminal absorption phenomenon, indicating the successful coupling of SWCNTs with HA. The relative amount of HA grafted onto the surface of SWCNTs was tested by thermal gravimetric analysis (Figure 2C). SWCNTs were thermally stable until $600^{\circ} \mathrm{C}$, while the weight loss peak of HA-NH appeared from $150^{\circ} \mathrm{C}$ to $550^{\circ} \mathrm{C}$. At $600^{\circ} \mathrm{C}$, HA-SWCNTs showed approximately $47.27 \%$ weight loss, suggesting the relative amount of HA grafted onto SWCNTs was $47.27 \%{ }^{29}$

In addition, the morphology of SWCNTs modified with HA was characterized by TEM, as shown in Figure 3A. SWCNTs have self-organizing feature, easy to form bundles and bundles of ring. Raw SWCNTs without modification assembled into bundles (Figure 3Aa) due to the strong role of van der Waals forces between hydrophobic SWCNTs. After modification with HA, partial surface of SWCNTs 

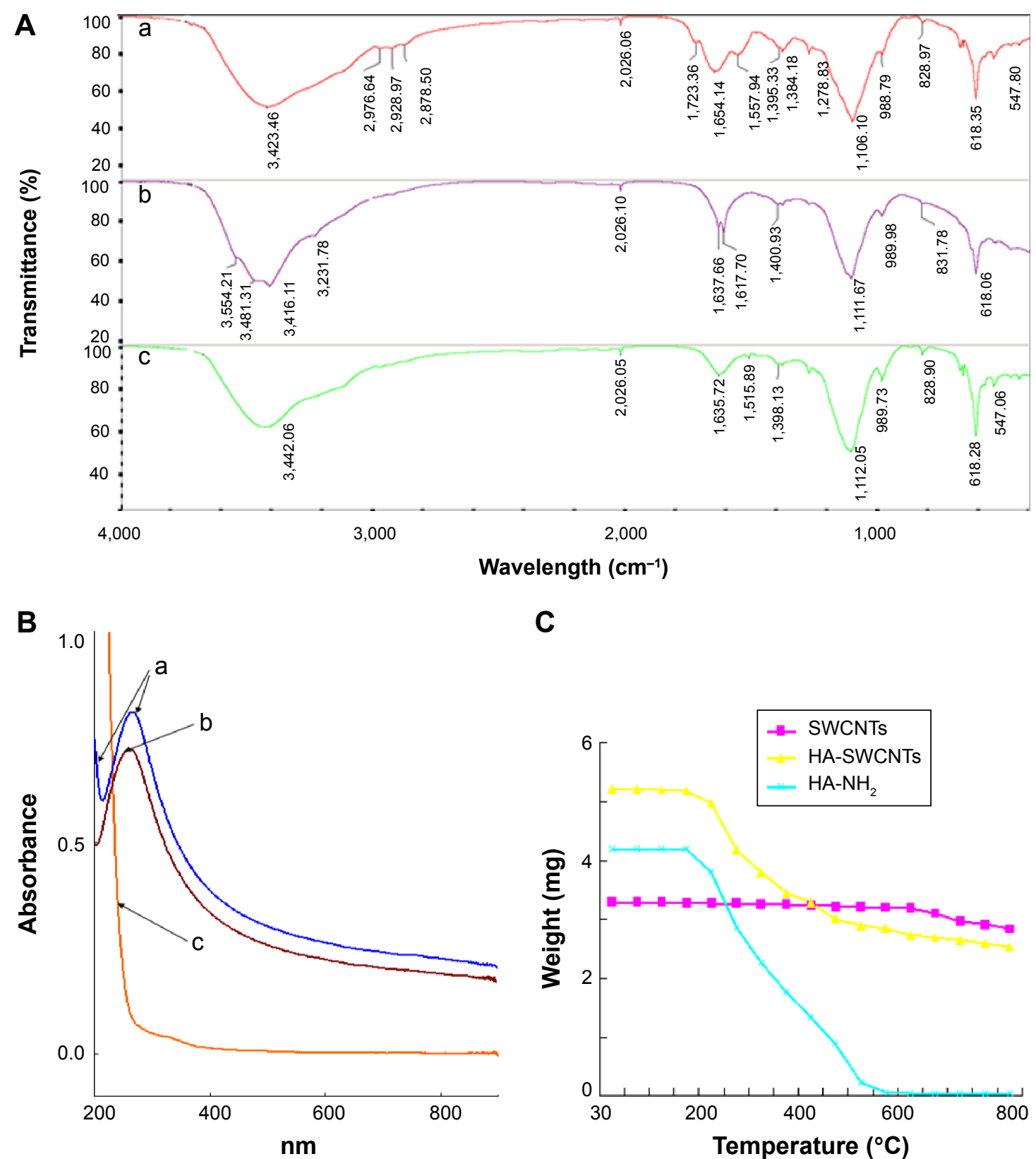

C

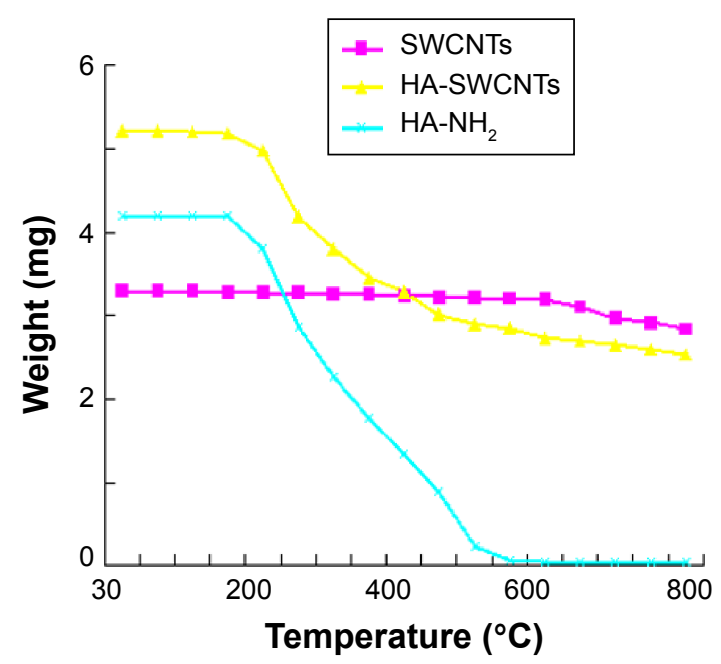

Figure 2 Characterization of HA-SWCNTs.

Notes: (A) FT-IR spectrum of (a) HA-SWCNTs, (b) HA-NH, and (c) HA; (B) UV spectrum of (a) HA-SWCNTs, (b) SWCNTs, and (c) HA-NH; (C) TGA curves. Abbreviations: FT-IR, Fourier transform infrared; HA, hyaluronic acid; HA-SWCNTs, hyaluronic acid-functionalized single-walled carbon nanotubes; SWCNTs, singlewalled carbon nanotubes; TGA, thermal gravimetric analysis; UV, ultraviolet.

changed to hydrophilic so that HA-SWCNTs did not assemble into bundle (Figure $3 \mathrm{Ab}$ ) and showed a good dispensability in aqueous solution. The particle size distribution was also characterized. Compared to SWCNTs $(56.72 \pm 5.96 \mathrm{~nm})$ (Figure 3C), HA-SWCNTs showed a much smaller size distribution of $28.54 \pm 3.53 \mathrm{~nm}$ (Figure 3D). The zeta potential of HA-SWCNTs was $-25.42 \pm 1.61 \mathrm{mV}$ (Figure 3B), suggesting that the nanodispersion in water was very stable.

\section{Preparation and characterization of Gd/HA-SWCNTs}

In this work, HA-SWCNTs were explored as "nanocapsules" for MRI-active $\mathrm{Gd}^{3+}$-ions. The $\mathrm{Gd}^{3+}$-ion loading may occur through the side-wall defects or end-of-tube openings. This CA harnessed the ability of HA-SWCNTs to encase smaller ions or molecules within their framework by successfully loading and confining aquated $\mathrm{Gd}^{3+}$ ion within the nanoscalar confines of the nanotubes. 
A
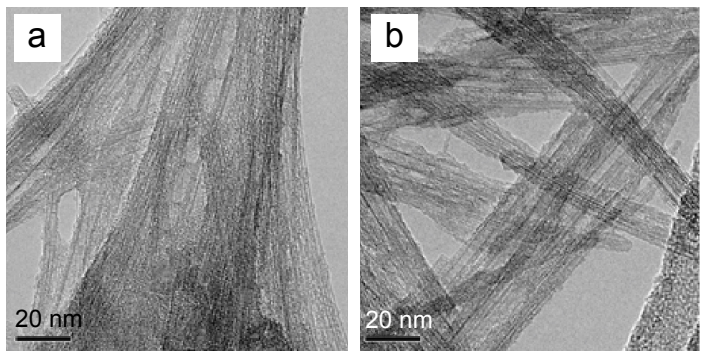

C

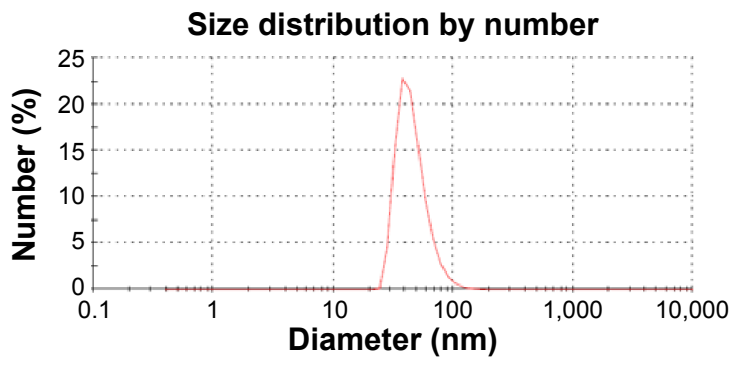

B

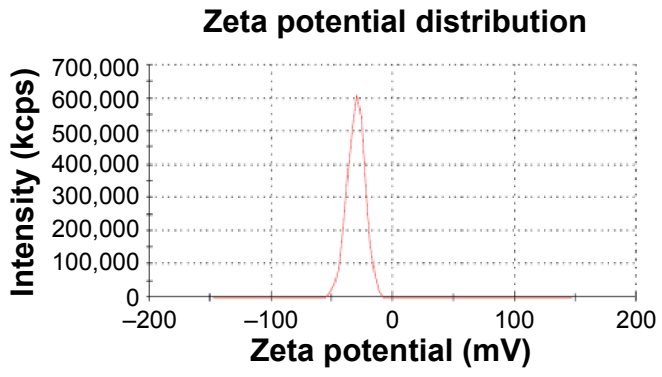

D

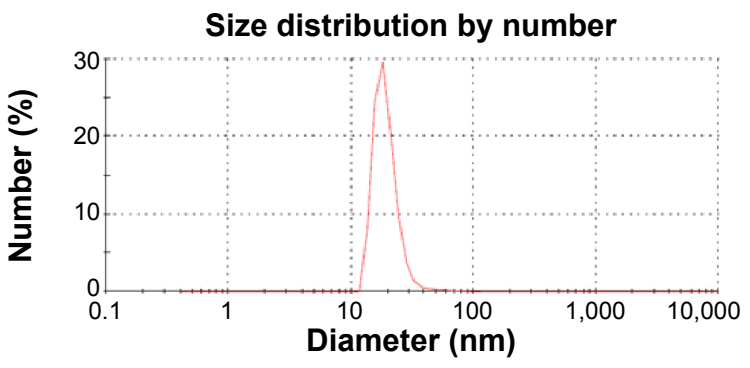

Figure 3 Characterization of HA-SWCNTs.

Notes: (A) TEM images of (a) SWCNTs and (b) HA-SWCNTs; (B) zeta potential of HA-SWCNTs; (C) size distribution of SWCNTs; (D) size distribution of HASWCNTs.

Abbreviations: HA-SWCNTs, hyaluronic acid-functionalized single-walled carbon nanotubes; SWCNTs, single-walled carbon nanotubes; TEM, transmission electron microscopy.

To determine the saturation level of $\mathrm{Gd}^{3+}$-ions loading onto HA-SWCNTs, different feed ratios of Gd/HA-SWCNTs were performed, indicating that loading efficiency increased with increasing amount of added $\mathrm{GdCl}_{3}$ (Figure 4A). A Gd loading of $24.3 \%$ (Gd/HA-SWCNTs weight ratio of 7/1) was chosen for the following experiments. The magnetization hysteresis loop further indicated the superparamagnetic nature of Gd/HA-SWCNTs (Figure 4B). Chelated Gd compounds have been widely used as $\mathrm{T}_{1}-\mathrm{CA}$ in MRI; ${ }^{8,9}$ owing to the presence of Gd on HA-SWCNTs, the nanocomposites can act as a $\mathrm{T}_{1} \mathrm{CA}$ for MRI.

Moreover, as shown in Figure 4C, compared with pristine SWCNTs (a), HA-SWCNTs (b), and Gd/HA-SWCNTs (d) were both stable in water over multiple weeks without significant aggregation, suggesting that HA-SWCNTs had excellent dispersibility in aqueous environments, good biocompatibility and the Gd/HA-SWCNTs dispersion was well soluble in water enough to be injected in an in vivo experiment and suitable for biomedical application.

\section{Cellular uptake}

Cellular uptake was performed to evaluate the intracellular transport capabilities of HA-SWCNTs for tumor cells (Figures 5 and 6). As shown in Figure 5, there was no significant difference among all time points of FITC group, suggesting that FITC alone could not enter into cancer cells, but just gathered on the cell surface. While green fluorescence detected in cells treated with SWCNTs and HA-SWCNTs both demonstrated a time-dependent manner. Besides, the uptake rank was HA-SWCNTs > SWCNTs, which was also evidenced by flow cytometer (Figure 6). The result indicated that HA-SWCNTs could effectively promote cellular uptake and then increase intracellular accumulation of Gd. And this distinction in uptake was probably owing to the presence of HA.

It had been demonstrated that HA nanoparticles showed rapid uptake into tumor cells and could enter tumor cells through receptor-mediated endocytosis, based on the interactions between the HA of nanotubes and CD44 of tumor cells. ${ }^{22,23} \mathrm{CD} 44$ was highly expressed on MCF-7 cells surface and, resulting in rapid uptake of HA-SWCNTs into tumor cells through receptor-mediated endocytosis.

\section{Safety evaluation}

The safety evaluation of this MRI CAs was investigated in vitro and in vivo. Cytotoxicity of the Gd/HA-SWCNTs was an important consideration for materials intended for in vivo application. Toward this goal, assessment of cell viability of MCF-7 cancer cells was examined. As shown in Figure 7, in vitro cytotoxicity study revealed that the cytotoxicity of 
A

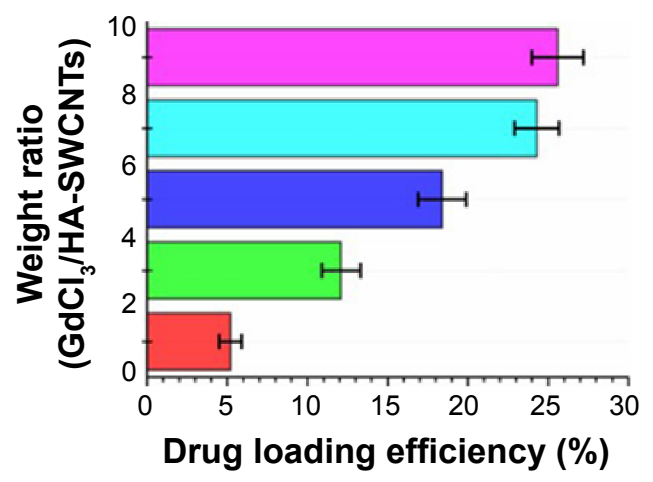

B

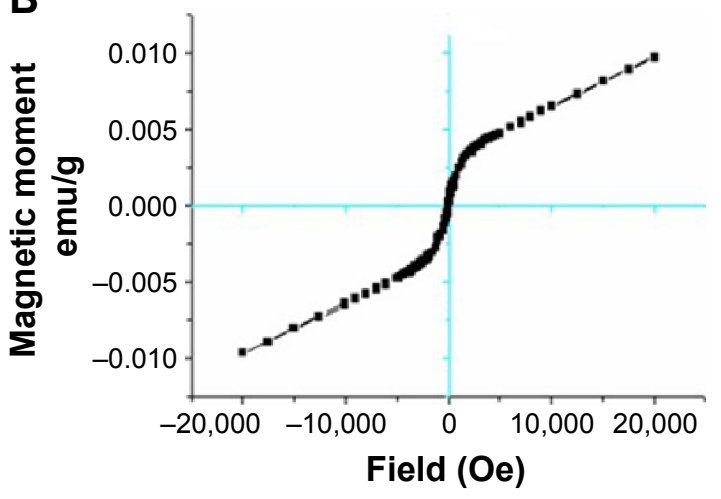

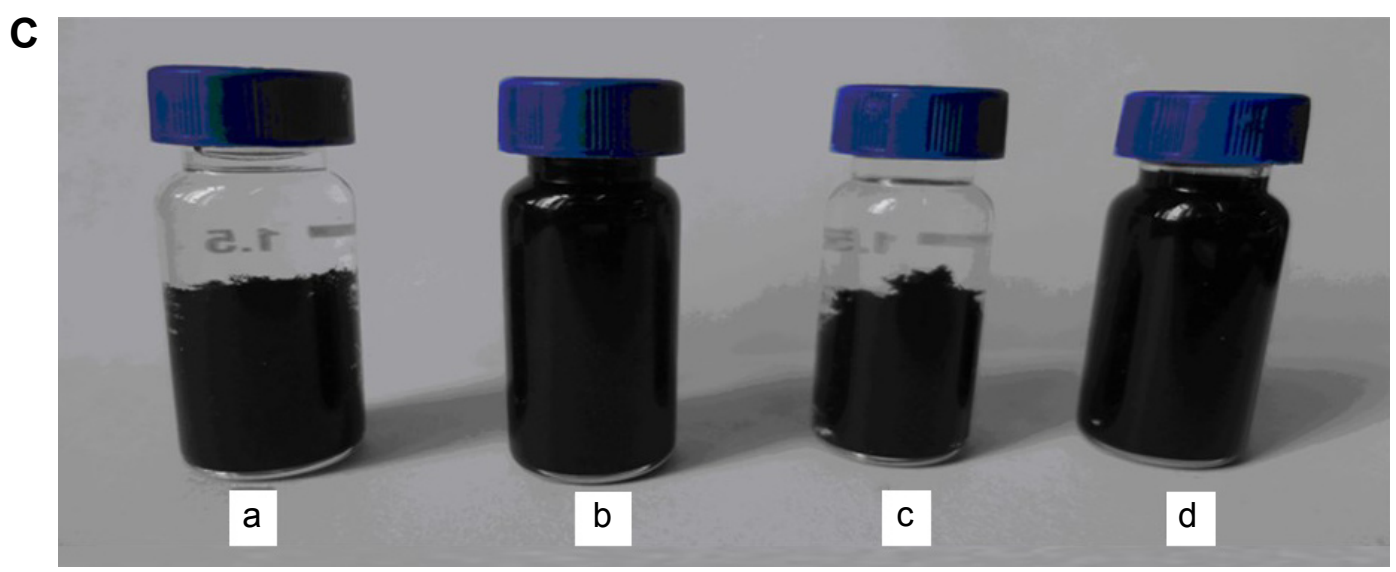

Figure 4 Characterization of Gd/HA-SWCNTs.

Notes: (A) $\mathrm{GdCl}_{3}$ loading at different feeding amounts of HA-SWCNTs; (B) magnetization loops of Gd/HA-SWCNTs; (C) dispersity of nanoparticles in water: (a) SWCNTs, (b) HA-SWCNTs, (c) Gd/SWCNTs, and (d) Gd/HA-SWCNTs.

Abbreviations: Gd/HA-SWCNTs, gadolinium/hyaluronic acid-functionalized single-walled carbon nanotubes; Gd/SWCNTs, gadolinium/single-walled carbon nanotubes; HA-SWCNTs, hyaluronic acid-functionalized single-walled carbon nanotubes; SWCNTs, single-walled carbon nanotubes.

Gd/HA-SWCNTs was lower than Gd/SWCNTs at all concentrations, indicating that the modification of HA could improve biocompatibility of SWCNTs. Meanwhile, Gd-DTPA, a MRI CA commonly used in clinical practice, was chosen as contrast reagent to evaluate the effect of Gd/HA-SWCNTs. Results demonstrated that at the same concentration of $\mathrm{Gd}$, the cytotoxicity of Gd/HA-SWCNTs was much lower than Gd-DTPA, suggesting HA-SWCNTs could stand as a biocompatible nanocarrier and Gd/HA-SWCNTs would be a relatively safe MRI CA in future.

Moreover, it demonstrated negligible systematic toxicity through the histopathological analysis, especially in liver and kidney (Figure 8). As shown in Figure 8, at the 1st day after administration, the hepatocytes were intact and cell nucleus staining was obvious in Gd/SWCNTs and Gd/ HA-SWCNTs groups, showing almost no toxicity. While Gd-DTPA group exhibited slight toxicity with balloon-like cells emerging and $\mathrm{GdCl}_{3}$ group presented acute toxicity with increased balloon-like cells and necrotic liver cell debris.
The renal toxicity results showed that no significant pathological changes were observed in Gd/SWCNTs, Gd/ HA-SWCNTs, and Gd-DTPA groups, while $\mathrm{GdCl}_{3}$ group presented slight toxicity, suggesting Gd/HA-SWCNTs was a relatively safe MRI CA in vivo. The physiological samples of the 5 th day and 10th day showed that there were no obvious pathological changes in liver and kidney of Gd/SWCNTs, Gd/HA-SWCNTs, and Gd-DTPA groups, while $\mathrm{GdCl}_{3}$ group also exhibited certain degree of liver toxicity. The aforementioned situation may be related with the metabolism of CAs and hepatic tissue regeneration.

Free Gd had high toxicity and it could cause rapid liver necrosis and induce multiple organ failure when the body contained an excess of free Gd. At present, MRI CAs used in clinical practice were Gd chelates. After being chelated, Gd could not only reduce the toxicity but also change its metabolism in the body to ensure image contrast. It was hard to isolate $\mathrm{Gd}$ from nanosuspended Gd/HA-SWCNTs in vivo, so the toxicity had been significantly reduced compared with $\mathrm{GdCl}_{3}$. 


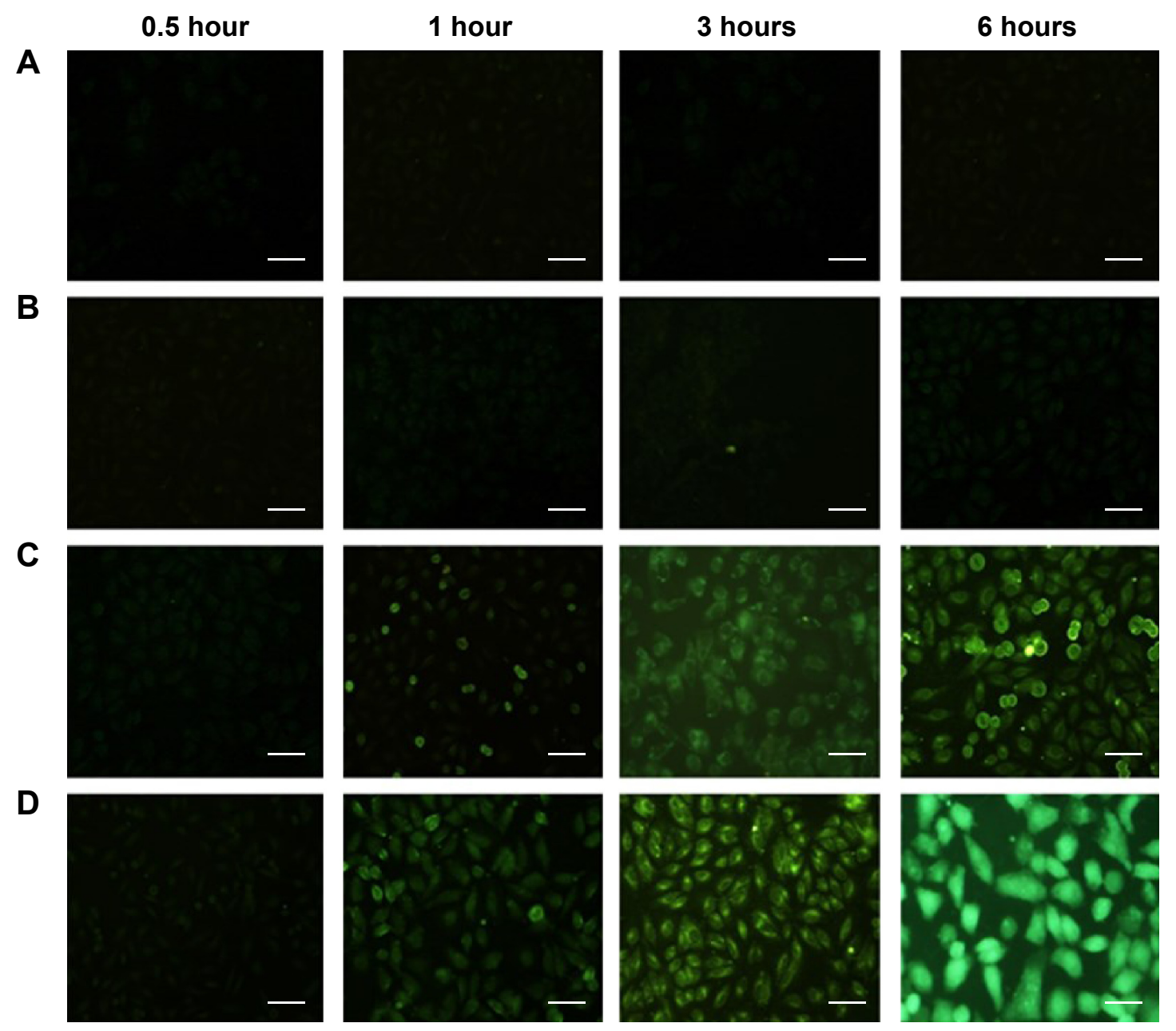

Figure 5 Uptake of SWCNTs and HA-SWCNTs in MCF-7 cell.

Notes: (A) Control group; (B) FITC group; (C) SWCNTs group; (D) HA-SWCNTs group. Scale bar corresponds to $10 \mu \mathrm{m}$.

Abbreviations: FITC, fluorescein isothiocyanate; HA-SWCNTs, hyaluronic acid-functionalized single-walled carbon nanotubes; SWCNTs, single-walled carbon nanotubes.

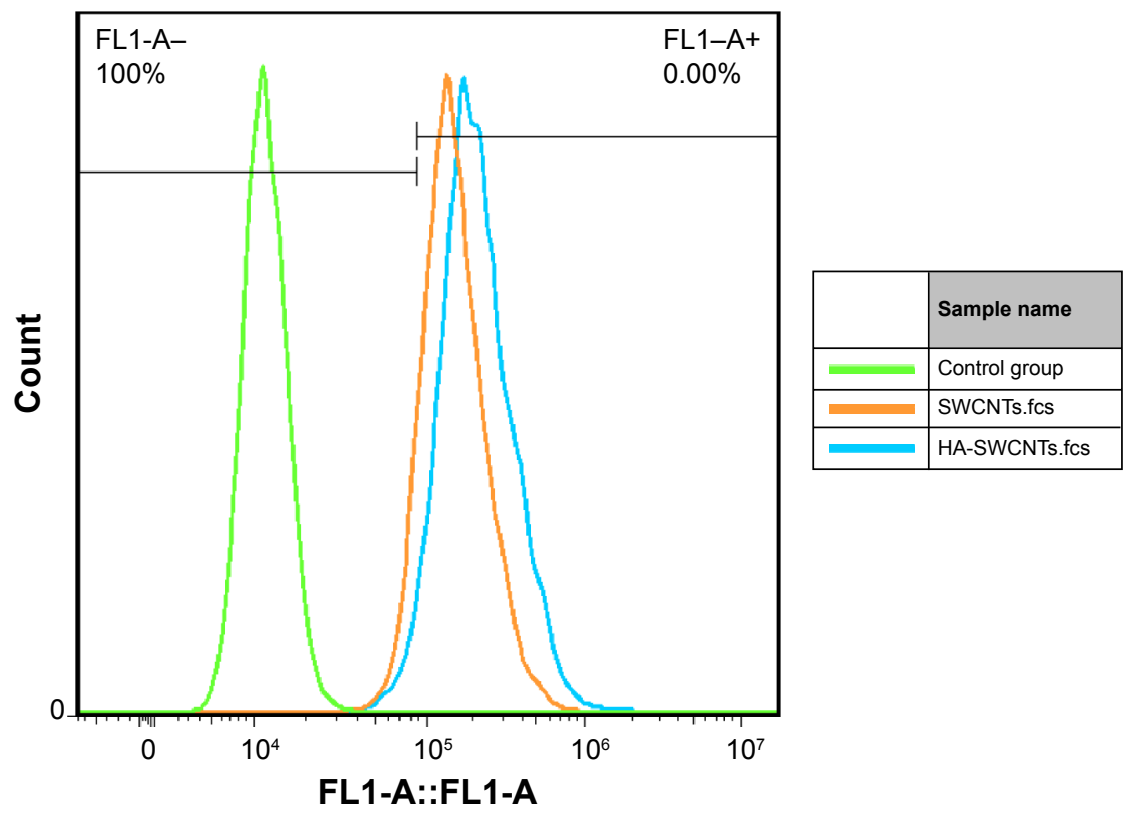

Figure 6 Uptake of SWCNTs and HA-SWCNTs in MCF-7 cell at 6 hours (the uptake of SWCNTs is $91.6 \%$, the uptake of HA-SWCNTs is $97.9 \%$ ).

Abbreviations: FLI-A, fluorescence; HA-SWCNTs, hyaluronic acid-functionalized single-walled carbon nanotubes; SWCNTs, single-walled carbon nanotubes. 


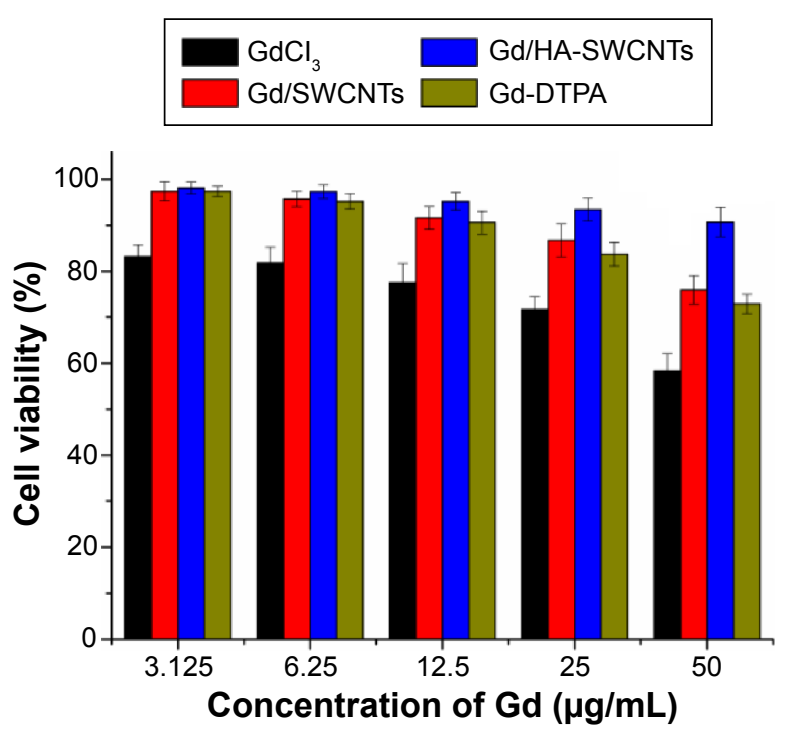

Figure 7 Cell viability of MCF-7 cells with different concentrations of Gd ${ }^{3+}$. Abbreviations: Gd/HA-SWCNTs, gadolinium/hyaluronic acid-functionalized singlewalled carbon nanotubes; Gd-DTPA, gadolinium (III)-diethylenediaminepentaacetic acid; Gd/SWCNTs, gadolinium/single-walled carbon nanotubes.

\section{Targeting efficiency study}

To understand the tumor-targeting efficiency of various Gd formulations $\left(\mathrm{GdCl}_{3}\right.$, $\mathrm{Gd} / \mathrm{SWCNTs}$, Gd/HA-SWCNTs, and Gd-DTPA), we determined content of Gd in tumor tissues of tumor-bearing mice and calculated area under the concentration-time curve (AUC) of Gd in tumors by 3 p97 software. It was observed that significant differences for the biodistribution of $\mathrm{Gd}$ in the four formulations existed (Figure 9). As Figure 9 shows, among all the groups, Gd/HASWCNTs group had the highest accumulated amount of Gd in tumor tissue (AUC: $14.6 \mathrm{mg} / \mathrm{h} * \mathrm{~L}$ ), followed by Gd/SWCNTs group (AUC: $10.5 \mathrm{mg} / \mathrm{h} * \mathrm{~L}$ ). While Gd-DTPA group, a kind of MRI CAs commonly used in clinical practice had much less accumulated Gd in tumor site (AUC: $4.7 \mathrm{mg} / \mathrm{h} * \mathrm{~L}$ ). This result indicated that HA modified SWCNTs had the highest tumor-targeting efficiency and the nanoscale HA-SWCNTs could be developed as a tumor-targeting carrier to deliver the

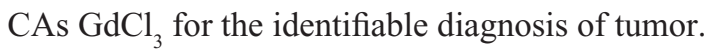

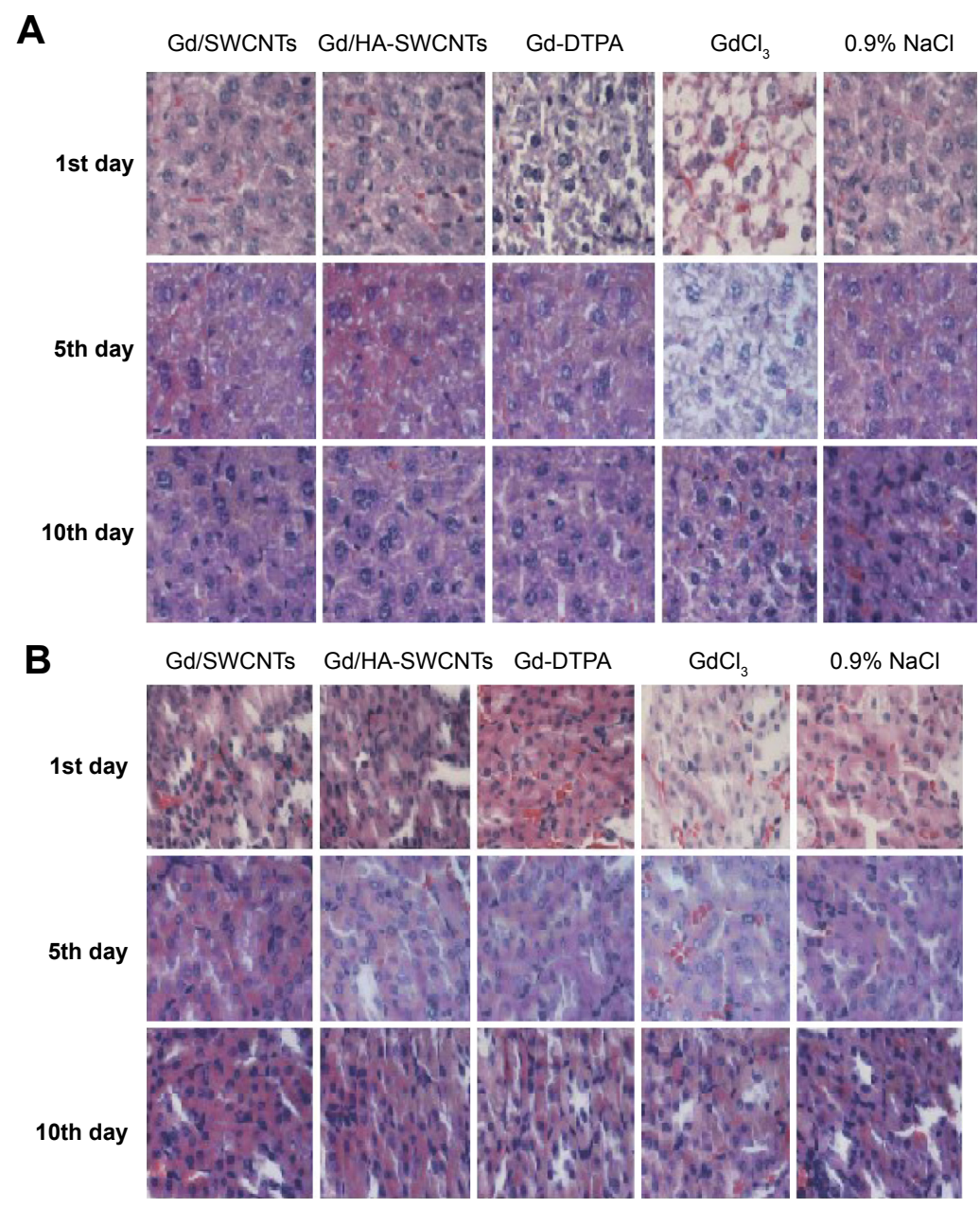

Figure 8 Histologic assessments of liver (A) and kidney (B) with H\&E staining in BALB/c mice.

Abbreviations: Gd-DTPA, gadolinium (III)-diethylenediaminepentaacetic acid; Gd/HA-SWCNTs, gadolinium/hyaluronic acid-functionalized single-walled carbon nanotubes; Gd/SWCNTs, gadolinium/single-walled carbon nanotubes; H\&E, hematoxylin-eosin. 


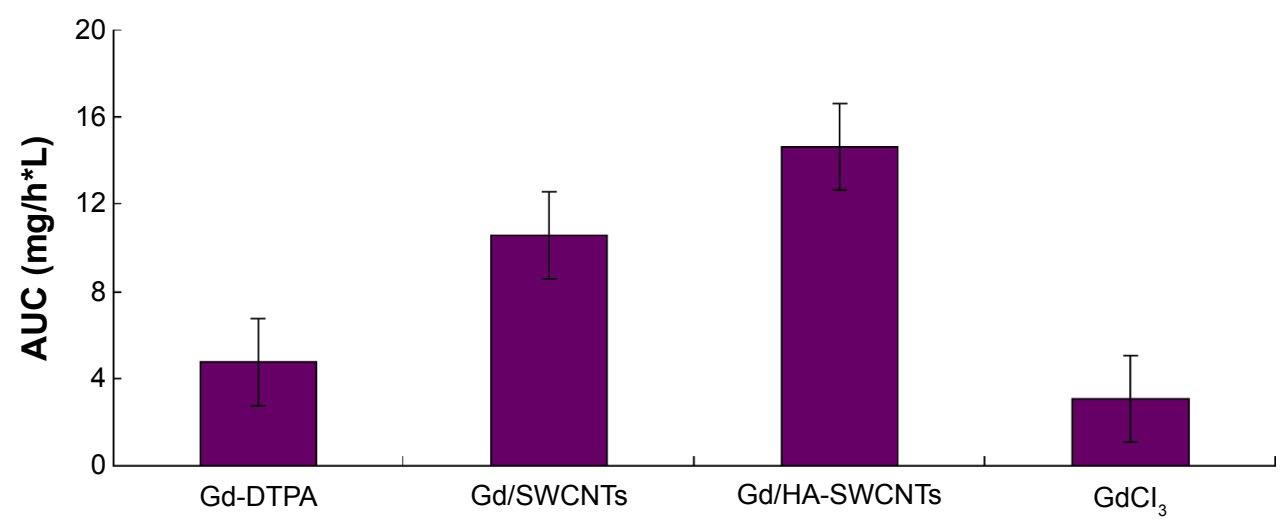

Figure 9 AUC values of tumor tissues after intravenous administration into tumor-bearing mice.

Abbreviations: AUC, area under the concentration-time curve; Gd-DTPA, gadolinium (III)-diethylenediaminepentaacetic acid; Gd/HA-SWCNTs, gadolinium/hyaluronic acid-functionalized single-walled carbon nanotubes; Gd/SWCNTs, gadolinium/single-walled carbon nanotubes.

In addition, from the results of ICP-OES measurement, besides tumor, the largest quantity of Gd/HA-SWCNTs in liver, representing $40 \%-50 \%$ of the total injected quantity, almost none were found in the spleen and kidney. The similar results were also observed from the H\&E staining.

\section{In vivo imaging analysis}

The effective use of nanoparticles for cancer diagnosis and therapy would be realized when in vivo biodistribution was clearly understood. In this study, HA-SWCNTs were labeled with the NIRF dye, DiR, to monitor in vivo biodistribution and tumor accumulation ability. It could be seen that fluorescent spectra of DiR (Figure 10A) and DiR-labeled HA-SWCNTs (Figure 10B) showed the similar profile and this result demonstrated that fluorescence of DiR would not be quenched by SWCNTs.

Figure 11 shows the real-time images of DiR-labeled HA-SWCNTs nanoparticles and the free DiR in the tumorbearing mice. After DiR-labeled HA-SWCNTs nanoparticles and the free DiR were given through the tail vein, timedependent biodistribution was observed. For the DiR-labeled HA-SWCNTs nanoparticles, considerable fluorescence signals were detected in most organs of the mice within 1 hour, resulting from circulation of nanoparticles in the bloodstream. Interestingly, the fluorescence intensity at the tumor site was strong and maintained on a high level up to 24 hours. On the contrary, for the free DiR, the fluorescence signals in the whole body of the mice decreased more quickly. In particular, compared with the free $\mathrm{DiR}$, the fluorescence intensity of the DiR-labeled HA-SWCNTs nanoparticles in the tumor region was much higher at any time post-injection ranging from 1 hour to 24 hours. These observations indicated that HA-SWCNTs nanoparticles increased the circulation time and resulted in highly selective accumulation at the tumor site. This result was consistent with the behavior of $\mathrm{Gd}$ in the formulation of Gd/HA-SWCNTs, suggesting that with the assistance of HA-SWCNTs nanocarrier, Gd could stay longer in body and accumulate more in tumor site.

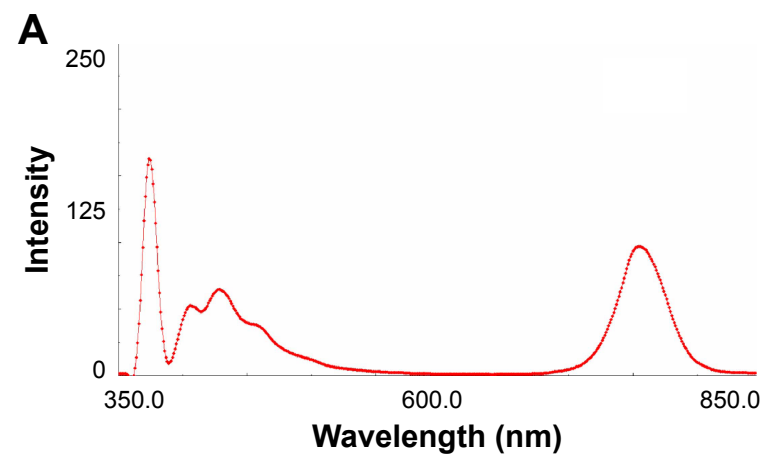

B

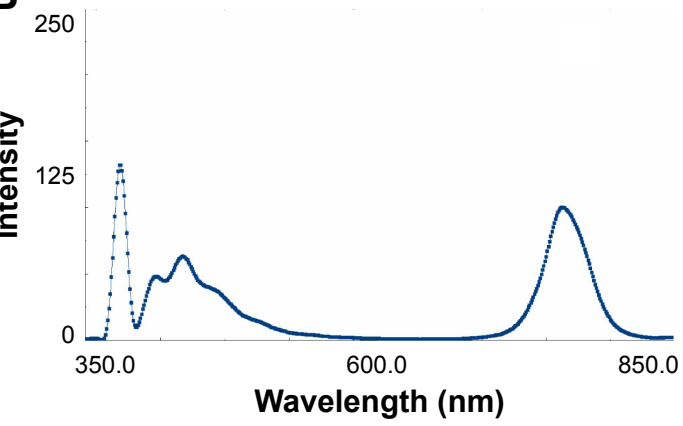

Figure 10 Fluorescence spectra of DiR (A) and DiR-labeled HA-SWCNTs (B) with excitation wavelength at $748 \mathrm{~nm}$ and emission wavelength at $790 \mathrm{~nm}$. Abbreviations: DiR, I,I'-dioctadecyltetramethyl indotricarbocyanine iodide; HA-SWCNTs, hyaluronic acid-functionalized single-walled carbon nanotubes. 


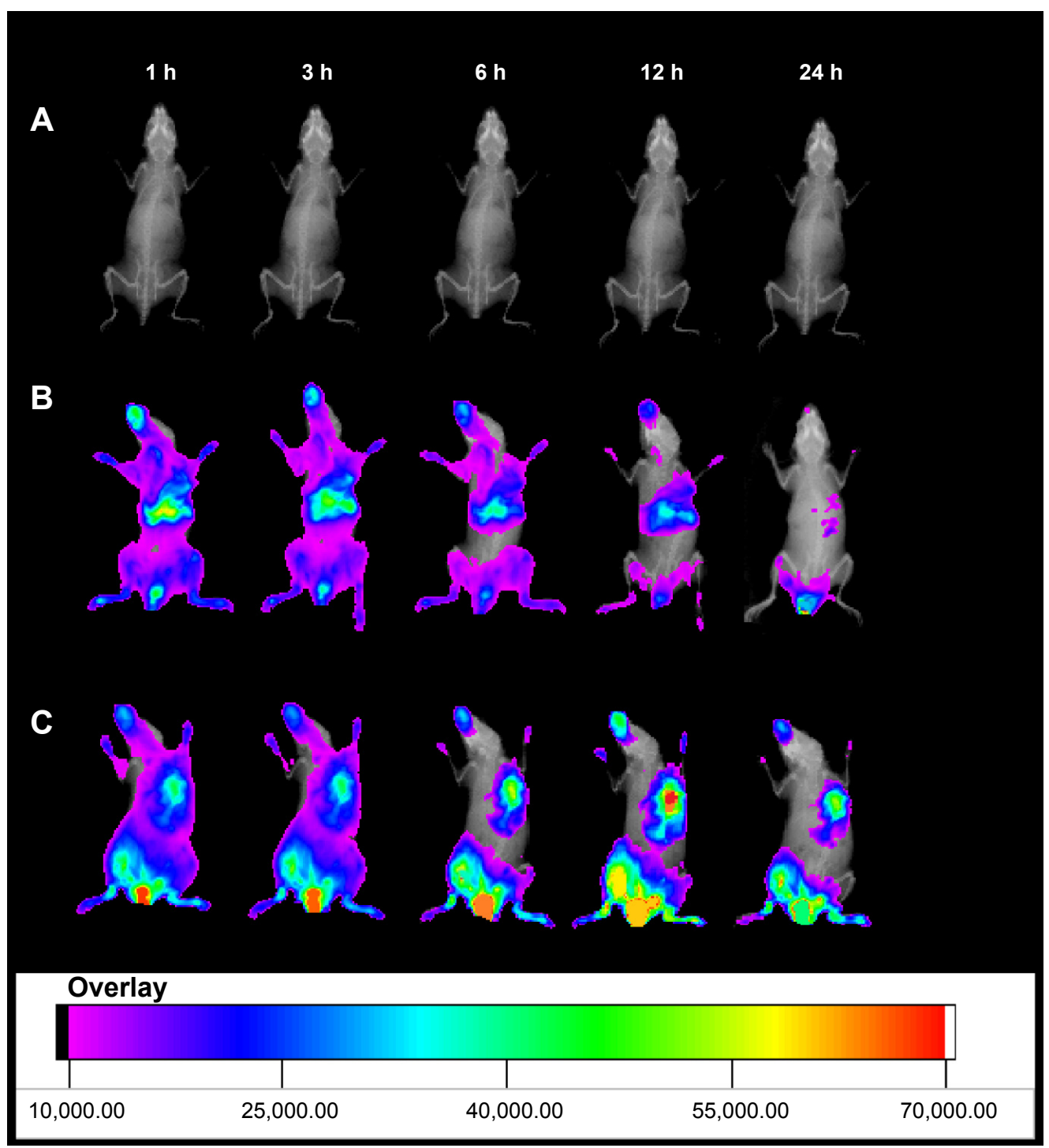

Figure I I In vivo non-invasive NIRF images of tumor-bearing mice.

Notes: (A) Control group; (B) free DiR; and (C) DiR-labeled HA-SWCNTs nanoparticles.

Abbreviations: DiR, I,I'-dioctadecyltetramethyl indotricarbocyanine iodide; h, hours; HA-SWCNTs, hyaluronic acid-functionalized single-walled carbon nanotubes; NIRF, near-infrared fluorescence.

Finally, to investigate the MRI contrast enhancing capabilities of Gd/HA-SWCNTs, $\mathrm{T}_{1}$-weighted MR images of tumor-bearing mice were acquired at 1 hour, 3 hours, and 24 hours post-injection (Figure 12). It showed that 1 hour after injection of Gd/HA-SWCNTs, the subcutaneous tumor appeared hyper intense. After that, the signal in tumor lesion increased gradually and the intense sustained until 24 hours. But for mice treated with Gd-DTPA, the signal enhancement was observed from 1 hour and then finally disappeared at 3 hours. These results suggested that nanoscale Gd/HA-SWCNTs MRI CA had the high $\mathrm{T}_{1}$-relaxivity enhancement and the coordination of free $\mathrm{Gd}^{3+}$ with HA-SWCNTs, minimizing $\mathrm{Gd}^{3+}$ release. So $\mathrm{Gd} /$ HA-SWCNTs could not only target the tumor site but also make $\mathrm{Gd}^{3+}$ stay in the tumor for a long time, to solve the problems of current clinical CAs with the poor targeting efficiency and short half-life.

\section{Conclusion}

In this study, HA-functionalized SWCNTs was developed as a tumor-targeting carrier to deliver the $\mathrm{CAs} \mathrm{GdCl}_{3}$ for the identifiable diagnosis of tumor. Gd/HA-SWCNTs suggested a low toxicity in clinical practice resulting from the high $\mathrm{T}_{1}$-relaxivity enhancement and the coordination of free Gd with HA-SWCNTs, minimizing Gd release, suggesting that this MRI CA Gd/HA-SWCNTs is promising for high-resolution MR molecular imaging of tumor with high safety. 

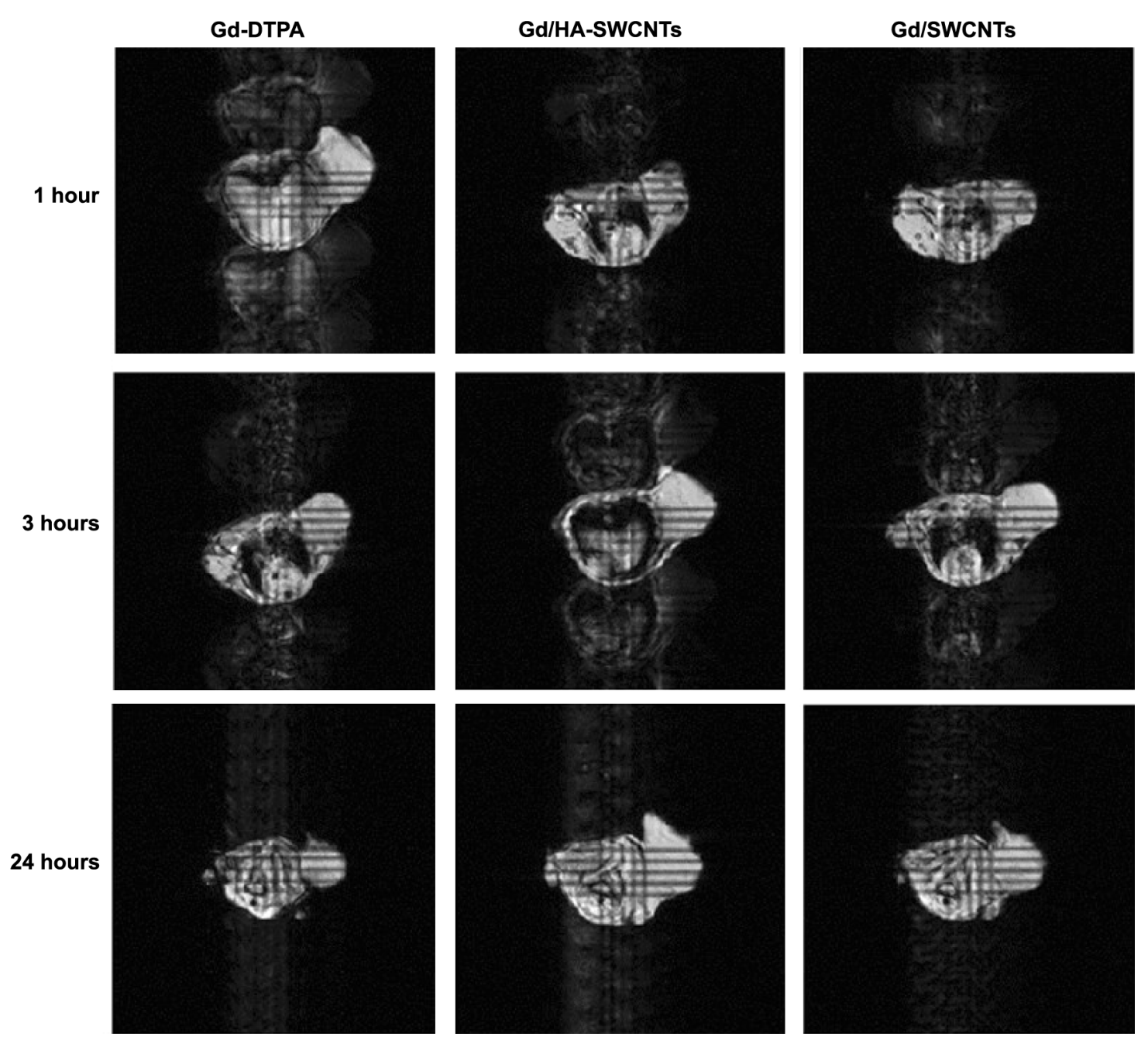

Figure 12 MRI of Gd-DTPA, Gd/HA-SWCNTs, and Gd/SWCNTs.

Abbreviations: Gd-DTPA, gadolinium (III)-diethylenediaminepentaacetic acid; Gd/HA-SWCNTs, gadolinium/hyaluronic acid-functionalized single-walled carbon nanotubes; Gd/SWCNTs, gadolinium/single-walled carbon nanotubes; MRI, magnetic resonance imaging.

\section{Acknowledgment}

This work was supported by grants from the National Natural Science Foundation of China (81202485 and 81273451).

\section{Disclosure}

The authors report no conflicts of interest in this work.

\section{References}

1. Merbach AE, Toth E. The Chemistry of Contrast Agents in Medical Magnetic Resonance Imaging. New York, DC: Wiley; 2001:484-485.

2. Richa S, Yuri M, Lon JW. The Gadonanotubes revisited: a new frontier in MRI contrast agent design. Inorganica Chim Acta. 2012;393: $165-172$.

3. Mansfield P. Snapshot magnetic resonance imaging (Nobel lecture). Angew Chem Int Ed Engl. 2004;43:5456-5464.

4. Geraldes CF, Laurent S. Classification and basic properties of contrast agents for magnetic resonance imaging. Contrast Media Mol Imaging. 2009; $4: 1-23$.

5. Sitharaman B, Wilson LJ. Gadonanotubes as new high-performance MRI contrast agents. Int J Nanomedicine. 2006;1:291-295.
6. Mogilireddy V, Déchamps-Olivier I, Alric C, et al. Thermodynamic stability and kinetic inertness of a Gd-DTPA bisamide complex grafted onto gold nanoparticles. Contrast Media Mol Imaging. 2014. doi:10.1002/cmmi.1616.

7. Xiao Y, Xue R, You T, et al. Gadolinium-1,4,7,10-tetraazacyclododecane1,4,7,10-tetraacetic acid conjugate of arabinogalactan as a potential liver-targeting magnetic resonance imaging contrast agent. Carbohydr Res. 2014;395:9-14.

8. AydinTekdaş D, Garifullin R, Sentürk B, et al. Design of a Gd-DOTAphthalocyanine conjugate combining MRI-contrast imaging and photosensitization properties as a potential molecular theranostic. Photochem Photobiol. 2014;90:1376-1386.

9. Richard C, Doan BT, Beloeil JC, et al. Noncovalent functionalization of carbon nanotubes with amphiphilic gd3+ chelates: toward powerful t1 and t2 MRI contrast agents. Nano Lett. 2008;8:232-236.

10. Bottini M, Rosato N, Bottini N. PEG-modified carbon nanotubes in biomedicine: current status and challenges ahead. Biomacromolecules. 2011;12:3381-3393.

11. Popov AM, Lozovik YE, Fiorito S, et al. Biocompatibility and applications of carbon nanotubes in medical nanorobots. Int $J$ Nanomedicine. 2007;2:361-372.

12. Jiao Z, Juanping L, Yuhong N, et al. Affinity and fluorescent detection of surfactants/ssDNA and single-walled carbon nanotube. Trans Nonferrous Met Soc China. 2013;23:456-461. 
13. Wang L, Shi J, Zhang H, et al. Synergistic anticancer effect of RNAi and photothermal therapy mediated by functionalized single-walled carbon nanotubes. Biomaterials. 2013;34:262-274.

14. Liu X, Tao H, Yang K, et al. Optimization of surface chemistry on single-walled carbon nanotubes for in vivo photothermal ablation of tumors. Biomaterials. 2011;32:144-151.

15. Gong H, Peng R, Liu Z. Carbon nanotubes for biomedical imaging: the recent advances. Adv Drug Deliv Rev. 2013;65:1951-1963.

16. Sitharaman B, Kissell KR, Hartman KB, et al. Superparamagnetic gadonanotubes are high-performance MRI contrast agents. Chem Commun. 2005;31:3915-3917.

17. Richard C, Doan BT, Beloeil JC, et al. Noncovalent functionalization of carbon nanotubes with amphiphilic gd3+ chelates: toward powerful t1 and t2 MRI contrast agents. Nano Lett. 2008;8:232-236.

18. Hasan T, Ehteram A. One-pot functionalization of short carboxyl multiwalled carbon nanotubes with ninhydrin and thiourea via microwave and thermal methods and their effect on the MKN-45 and MCF7 cancer cells. Fullerenes Nanotubes Carbon Nanostruct. 2014;22:833-834.

19. Hasan T, Mirosanloo A. One-pot and three component functionalization of short multi-walled carbon nanotubes with isatoic anhydride and benzyl amine and their effect on the MKN-45 and MCF7 cancer cells. Fullerenes Nanotubes Carbon Nanostruct. 2015;23:500-508.

20. Hasan T, Esmail B. Functionalization of carboxylated multi-wall nanotubes with 3,5-diphenyl pyrazole and their toxicity investigations. New Carbon Mater. 2013;28:199-207.

21. Hasan T, Hosna G. Functionalization of short multi-walled carbon nanotubes with creatinine and aromatic aldehydes via microwave and thermal methods and their influence on the MKN45 and MCF7 cancer cells. C R Chim. 2013;16:838-844.
22. Hasan T, Mina A, Saeed HK. Functionalization and toxicity effect of multi-walled carbon nanotubes with urea derivatives via microwave irradiation. Fullerenes Nanotubes Carbon Nanostruct. 2013;21: 568-578.

23. Hasan T, Yaser A, Saeed H. Synthesis, characterization, and toxicity investigations of functionalized multi-walled carbon nanotubes with creatinine and creatinine and 2-aminobenzophenone on the gastric cancer cells. Bull Korean Chem Soc. 2013;34:149-153.

24. Choi KY, Chung H, Min KH, et al. Self-assembled hyaluronic acid nanoparticles for active tumor targeting. Biomaterials. 2010;31:106-114.

25. Liu Y, Sun J, Cao W, et al. Dual targeting folate-conjugated hyaluronic acid polymeric micelles for paclitaxel delivery. Int J Pharm. 2011;421: 160-169.

26. Toole BP, Wight TN, Tammi MI. Hyaluronan-cell interactions in cancer and vascular disease. J Biol Chem. 2002;277:4593-4596.

27. Brown TJ. The development of hyaluronan as a drug transporter and excipient for chemotherapeutic drugs. Curr Pharm Biotechnol. 2008; 9:253-260.

28. Yoon HY, Koo H, Choi KY, et al. Tumor-targeting hyaluronic acid nanoparticles for photodynamic imaging and therapy. Biomaterials. 2012;33: 3980-3989.

29. Shi J, Ma R, Wang L, et al. The application of hyaluronic acidderivatized carbon nanotubes in hematoporphyrin monomethyl etherbased photodynamic therapy for in vivo and in vitro cancer treatment. Int J Nanomedicine. 2013;8:2361-2373.
International Journal of Nanomedicine

\section{Publish your work in this journal}

The International Journal of Nanomedicine is an international, peerreviewed journal focusing on the application of nanotechnology in diagnostics, therapeutics, and drug delivery systems throughout the biomedical field. This journal is indexed on PubMed Central, MedLine, CAS, SciSearch ${ }^{\circledR}$, Current Contents ${ }^{\circledR} /$ Clinical Medicine,

\section{Dovepress}

Journal Citation Reports/Science Edition, EMBase, Scopus and the Elsevier Bibliographic databases. The manuscript management system is completely online and includes a very quick and fair peer-review system, which is all easy to use. Visit http://www.dovepress.com/ testimonials.php to read real quotes from published authors. 